\title{
Spatiotemporal dynamics of habitat suitability for the Ethiopian staple crop, Eragrostis tef (teff), under changing climate
}

\author{
Dinka Zewudie ${ }^{1}$, Wenguang Ding ${ }^{\text {Corresp., } 1}{ }^{\text {, }}$ Zhanlei Rong ${ }^{2}$, Chuanyan Zhao ${ }^{3}$, Yapeng Chang ${ }^{3}$ \\ ${ }^{1}$ College of Earth and Environmental Sciences, Lanzhou University, Lanzhou 730000, China, Lanzhou, China \\ 2 College of Geographical Science, Qinghai Normal University, Xining 810008, China, Lanzhou, China \\ ${ }^{3}$ State Key Laboratory of Grassland Agro-ecosystems, College of Pastoral Agriculture Science and Technology, Lanzhou University, Lanzhou 730000, \\ China, Lanzhou, China \\ Corresponding Author: Wenguang Ding \\ Email address: wgding@lzu.edu.com
}

Teff (Eragrostis tef (Zucc.) Trotter) is a staple, ancient food crop in Ethiopia. Its growth is affected by climate change, so it is essential to understand climatic effects on its habitat suitability in order to design countermeasures to ensure food security. Based on the four Representative Concentration Pathway emission scenarios (i.e. RCP2.6, RCP4.5, RCP6.0 and RCP8.5) set by the Intergovernmental Panel on Climate Change (IPCC), we predicted the potential distribution of teff under current and future scenarios using a maximum entropy model (Maxent). Eleven variables were selected out of 19, according to correlation analysis combined with their contribution rates to the distribution. Simulated accuracy results validated by the area under the curve (AUC) had strong predictability with values of 0.83-0.85 for current and RCP scenarios. Our results demonstrated that mean temperature in the coldest season, precipitation seasonality, precipitation in the cold season and slope are the dominant factors driving potential teff distribution. Proportions of suitable teff area, relative to the total study area were $58 \%$ in current climate condition, 58.8\% in RCP2.6, $57.6 \%$ in RCP4.5, 59.2\% in RCP6.0, and 57.4\% in RCP8.5, respectively. We found that warmer conditions are correlated with decreased land suitability. As expected, bioclimatic variables related to temperature and precipitation were the best predictors for teff suitability. Additionally, there were geographic shifts in land suitability, which need to be accounted for when assessing overall susceptibility to climate change. The ability to adapt to climate change will be critical for Ethiopia's agricultural strategy and food security. A robust climate model is necessary for developing primary adaptive strategies and policy to minimize the harmful impact of climate change on teff. 
1 Spatiotemporal dynamics of habitat suitability for the Ethiopian staple crop, Eragrostis tef (teff), under changing climate

Q Wenguang Ding (Corresponding author) , wgding@1zu.edu.com

\section{Abstract}

Teff (Eragrostis tef(Zucc.) Trotter) is a staple, ancient food crop in Ethiopia. Its growth is affected by climate change, so it is essential to understand climatic effects on its habitat suitability in order to design countermeasures to ensure food security. Based on the four Representative Concentration Pathway emission scenarios (i.e. RCP2.6, RCP4.5, RCP6.0 and RCP8.5) set by the Intergovernmental Panel on Climate Change (IPCC), we predicted the potential distribution of teff under current and future scenarios using a maximum entropy model (Maxent). Eleven variables were selected out of 19, according to correlation analysis combined with their contribution rates to the distribution. Simulated accuracy results validated by the area under the curve (AUC) had strong predictability with values of $0.83-0.85$ for current and RCP scenarios. Our results demonstrated that mean temperature in the coldest season, precipitation seasonality, precipitation in the cold season and slope are the dominant factors driving potential teff distribution. Proportions

26 of suitable teff area, relative to the total study area were $58 \%$ in current climate condition, $58.8 \%$

27 in RCP2.6, 57.6\% in RCP4.5, 59.2\% in RCP6.0, and 57.4\% in RCP8.5, respectively. We found 
28 that warmer conditions are correlated with decreased land suitability. As expected, bioclimatic

29 variables related to temperature and precipitation were the best predictors for teff suitability.

30 Additionally, there were geographic shifts in land suitability, which need to be accounted for when

31 assessing overall susceptibility to climate change. The ability to adapt to climate change will be

32 critical for Ethiopia's agricultural strategy and food security. A robust climate model is necessary

33 for developing primary adaptive strategies and policy to minimize the harmful impact of climate

34 change on teff.

35

36 Keywords: climate change, Ethiopia, Maxent, potential distribution, Eragrostis tef

37 


\section{Introduction}

40 Climate is the key controlling factor in the distribution of species, and variations in habitat

41 distribution patterns can be attributed to climate change (Parmesan \& Yohe, 2003; Lenoir et al., 42 2008; Bertrand et al., 2011; Guo et al. 2016). The global average surface temperature has caused 43 warming of $0.8{ }^{\circ} \mathrm{C}$ over the past century (Hansen et al. 2006; Yumbya et al. 2014), and is 44 accelerating, with a $0.6^{\circ} \mathrm{C}$ increase in the last four decades (Hansen et al. 2010; Suwannatrai et al. 2017). International Panel on Climate Change (IPCC, 2007) reports that over the course of this century, net carbon uptake by the terrestrial ecosystem made a peak mid-century and then weakened or even reversed the increase on climate change. Global average temperature increases exceeding the $1.5-2.5^{\circ} \mathrm{C}$ range and the concomitant $\mathrm{CO}_{2}$ concentration, is projected to trigger major changes in the ecosystem structure and function, alter species ecological interactions and produce shifts in species' geographical ranges with predominantly negative consequences for biodiversity and ecosystem goods and services, e.g. water and food supply (Kumar 2012; Liao \& Chang 2014; Pachauri et al. 2014). Evidence suggests that a significant impact of global warming is already discernible in animal and plant populations (Root et al. 2003).

Temperature in Africa is expected to increase faster than the global average throughout the $21 \mathrm{st}$ century (Christensen et al., 2007; Joshi et al., 2011; James and Washington, 2013). However, future values for Africa estimated by the International Panel on Climate Change (IPCC 2007) are relatively uncertain (Solomon et al. 2007). In particular, Ethiopia is predicted to be highly vulnerable to climate change, manifesting an increased warming accompanied by inconsistent rainfall leading to decreased crop security (Conway \& Schipper 2011). Climate change may increase the risk for food production in many African countries as their agricultural systems are mostly rain-fed. These impacts on livelihood, will undoubtedly mean that 
62 countries will have to change their farming policies (Dinar 2007). In Ethiopia, agriculture plays a

63 crucial role in enhancing economic growth and contributes up to half of the Gross Domestic

64 Product (GDP) (Gebrehiwot \& Van Der Veen 2013). Despite being one of the largest cereal

65 producers in East Africa, the country is still not self-sufficient; 85\% of Ethiopians live in agrarian

66 areas relying on agricultural production as means of living (Gebrehiwot \& Van Der Veen 2013).

67 Moreover, many rural Ethiopians face long or short seasonal droughts, leading to crop failure

68 (Tefera \& Quintin 2012; Kamali et al. 2018). "Green famines" are caused in Ethiopia by a seasonal

69 pattern shift with delayed rains for several weeks or starting and stopping suddenly in critical

70 germination periods. Consequently, crops are lost while the natural vegetation is able to resume

71 normal phenological cycles, thus providing a green landscape (Evangelista et al. 2013). Changing

72 patterns of drought and precipitation in Ethiopia have already been documented by other

73 researchers, and greater changes are expected under future conditions (Deressa \& Hassan 2009;

74 Viste et al. 2013). Cereal crops face an especially critical threat due to climate change (Ledig et

75 al. 2010), affecting human populations that rely on only a few edible species for nutrition and

76 sustenance out of more than 50,000 known edible species available worldwide (Cheng et al. 2017).

77 Teff (Eragrostis tef (Zucc.) Trotter), is an ancient and major staple food crop in Ethiopia,

78 accounting for the largest share of land cultivation for cereal crops, $24 \%$ nationwide (Taffesse et

79 al. 2012), showing a wide geographic condition and marked plasticity by growing in 10 to 18 agro

80 ecological zones (Assefa et al., 2001). Teff is a warm-season annual crop that produces very small

81 grains and is also gluten-free and high in iron (Figure 1A) (Rosell et al. 2014). Teff contains a

82 huge amount of nutrients, and moreover is tolerant of extremes such as drought, Water logging,

83 pests, and diseases (Cheng et al. 2017). 
84 Teff crops occupy nearly $30,000 \mathrm{~km}^{2}$ (CSA 2014) about $30 \%$ of the total area covered by cereals

85 in all administrative regions, predominantly on the highlands of Tigray, Amhara, Oromia, and

86 SNNPR regions (Wondimu and Tekabe 2001). Teff growth has been reported at altitudes up to

873000 m.a.s.l. ranging from semiarid areas with low rainfall to areas with high rainfall. Under

88 current conditions, teff is suitable in most areas of the country covering diverse agro ecological

89 regions where millions of people rely on it as a daily food--indeed, nearly $60 \%$ of the Ethiopian 90 population.

91 However, due to climate change, it is one of the most vulnerable crops in the region (Evangelista 92 et al. 2013). It is estimated that enjera, made from teff, provides up to two-thirds of the food consumed by Ethiopians (Figure 1B) (Cheng et al. 2017; VanBuren et al. 2020). Therefore,

94 predicting potential teff distribution is necessary to take safe and effective countermeasures to 95 reduce its ecological risk under climate change (Kamilar et al. 2013).

96 Maxent is an ecological tool and statistical model used to examine ecological processes and 97 interactions across spatial and temporal scales (Elith et al. 2006; Phillips et al. 2006) that has been 98 employed to explore a range of species, habitats and ecosystem conditions (Alberto et al. 99 2013;Brown et al., 2014; Beltramino et al. 2015). Species distribution models (SDMs) are a subset 100 of the approaches outlined and were developed by combining current and historical species 101 distribution data with relevant environmental variables to explain both occurrence and abundance 102 of organisms in ecosystems (Peterson et al., 2006; Zimmermann et al., 2010; Caminade et al., 103 2012; Kamilar et al. 2013; Guo et al. 2017b). A variety of SDMs have been developed to predict 104 species distributions under different climate scenarios (e.g. RCP). Commonly used SDM models 105 including the Genetic Algorithm for Rule-set Production (GARP), BIOCLIM and Ecological

106 Niche Factor Analysis (ENFA) have proved to be essential for predicting target species 
107 distributions under current, and also future climate scenarios (Rong et al. 2019; Tognelli et al.

108 2009). Maxent (maximum entropy) has been widely used due to its many advantages, including

109 its ability to: deal with incomplete data, small sample size, species presence data, both continuous

110 and categorical environmental data; reduce laborious jobs in data collection; facilitate model

111 interpretation, and for its prediction accuracy and reliability (Guo et al. 2017a; Rong et al. 2019).

112 SDMs assume that available presence locations represent a random (representative) sample in the

113 geographical space, with no spatial dependencies and bolstered by data-rich technologies, such as

114 geographical information systems (GIS) (Rushton et al. 2004, Elith et al. 2011).

115 Teff had been an important crop in the past and will continue to be a staple food for the majority

116 of the Ethiopian people in the future. Being a major staple crop, teff is an essential food in Ethiopia,

117 so any impact on suitable areas for its cultivation due to climate change will have a direct impact

118 on food security. Unfortunately, there is already a huge deficit between teff production and the

119 national demand, which will be exacerbated by the effects of climate change. Therefore, as long

120 as teff production decreases against a rising demand due to Ethiopia's fast-growing population,

121 the teff price will increase. As cultural food insecurity remains widespread in Ethiopia, policy

122 makers should pay attention to areas with low habitat suitability and resilience for teff. It is

123 important to maintain nutrition and sustainable food security for the Ethiopian people with the

124 implementation of a strategy to foster diversification and avoid over reliance on this crop.

125 In a climate change context, understanding and planning for crop resilience is crucial for protection

126 of global food supplies, and therefore research on key crops is needed for decision makers to plan

127 and strategize future actions (Cowie et al. 2018). In line with this, the major objectives of this study

128 are to: (1) predict the potential distribution of teff species under current climates; (2) forecast

129 suitable areas for teff species under four future climate scenarios, and (3) evaluate the effects of 
130 climate change on teff distribution. Identifying shifts in the ranges of suitable areas under future

131 scenarios is a novel approach in the study and we also shown the full workflow on which every

132 step of analyses of our work is delineated in Figure 2.

133

Figure 1. A. Teff (Eragrostis tef), a fine-grain annual cereal. (Source: FAO http://www.fao.org/traditional-crops/teff/en/); B. Teff-made enjera is a staple food product in Ethiopia.

135

Figure 2 The workflow shows that data sets of two topographic data and Climatic Variables (Bio1Bio19) for multicollinearity test and Variables importance with Species occurrence presence only data with MAXENT and then Teff distribution prediction based on multiple climate conditions scenarios.

\section{Materials and Methods}

139 In this study, we analyzed the geographic distribution of Eragrostis tef occurrence from Ethiopian

140 Biodiversity Institute (EBI) (https://www.ebi.gov.et/) and Ethiopian National Herbarium, Addis

141 Ababa University with Maxent climate envelope model (CEM) under four climate change

142 scenarios.

\subsection{Study Area}

145 Ethiopia lies in northeast Africa, and is located between latitude $3.30^{\circ}-15^{\circ} \mathrm{N}$ and longitude $33^{\circ}-$

$14648^{\circ} \mathrm{E}$ covering $1.13 \times 10^{6} \mathrm{~km}^{2}$ with heterogenous landscapes including mountains, hills, and flat

147 regions with elevations from below sea level to more than 4,000 m.a.s.l. (Tilahun \& Schmidt 2012)

148 (Figure 3). Due to this varied relief, Ethiopia has a variety of climates going from desert climate

149 to that typical of equatorial mountains (tropical) with three major climatological seasons: June-

150 September (called Kiremt), October-January (Bega), and February-May (Belg) (Gissila et al.

151 2004; Korecha \& Barnston 2007; Fazzini et al. 2015). Annual average temperature ranges from 10 
152 to $27^{\circ} \mathrm{C}$ and precipitations vary across the country and season from 145 to $2,100 \mathrm{~mm}$ annually

153 (Hordofa et al. 2008; Fazzini et al. 2015).

154

Figure 3 Locations of sampling sites and land elevation within the nine Ethiopian regional state administrations: Oromia, Amhara, Tigray, Afar, Benishangul-Gamuz, Gambella, Harari, Southern Region, and Somali Region.

\section{$156 \quad 2.2$ Crop production in Ethiopia}

157 Though agricultural planning is difficult due to variable rainfall, a large proportion of Ethiopia

158 receives sufficient rain for crop production, that is mostly sown from June to October and harvested

159 from September to February (Taffesse et al. 2012). The primary crop season corresponds to the

160 summer rainy season, from June to August and in the autumn from September to November

161 (Yumbya et al. 2014). Light rains also fall during spring, from March through May. Some crops -

162 only about $8 \%$ of total crop land- are harvested between March and August, making Ethiopia's

163 crop season somewhat bimodal (Hordofa et al. 2008; Taffesse et al. 2012). Teff grows primarily

164 in the highlands where clouds are forced to release rain. The optimal growing conditions for teff

165 are $430-560 \mathrm{~mm}$ of rain per year and a temperature range of $10-30^{\circ} \mathrm{C}$ (Roseberg et al. 2005).

\section{$166 \quad$ 2.3 Teff Distribution Data}

167 The distribution dataset contains 2490 verified, geo-referenced data-points (latitude, longitude and

168 altitude) belonging to germplasm collections and herbarium specimens from the gene bank of the

169 Institute of Biodiversity Conservation, and 14 specimens from the Ethiopian National Herbarium,

170 Addis Ababa University, collected between 1978 and 2019. Teff was present in all sites over the

171 nine Ethiopian regional state administrations, predominantly in the Oromia, Amhara, Tigray, the 
172 Southern Nations, and Harari regions, with only a few locations in Gambela, Beninshangul-

173 Gumuz, and the Somali Region, and had no significant presence in Afar.

\section{$174 \quad 2.4$ Topographical data}

175 The Digital Elevation Model (DEM) with a 90-meter special resolution was acquired from the

176 USGS Shuttle Radar Topography Mission dataset (www.srtm.usgs.gov). Two terrain variables

177 (aspect and slope) from the DEM were re-sampled into $1 \mathrm{~km}$ spatial resolution using neighbor

178 sampling in ArcGIS 10.5. The two topographical variables were used as model inputs.

\section{$179 \quad 2.5$ Current and future climate data}

180 Climatic data consisting of 19 bioclimatic variables, here coded Bio1 through Bio19, were

181 obtained from the WorldClim (http://www.worldclim.org/) at $30^{\prime \prime}$ resolution $(1 \mathrm{~km} \times 1 \mathrm{~km})$ for the

182 climate from 1950 to 2000 in the study area (Fick \& Hijmans 2017). The dataset comprises global

183 gridded information with $1 \mathrm{~km}$ spatial resolution on past, current, and future scenarios

184 (http://www.worldclim.org/).

185 Future climate data is based on the standard scenarios of the Fifth Assessment Report from the

186 IPCC (IPCC 2013). All four greenhouse gas concentration trajectories provided by the IPCC were

187 used, Representative Concentration Pathway (RCP): RCP 2.6, RCP 4.5, RCP 6.0, and RCP 8.0. In

1882100 , the total radiative forcing values in the four scenarios stated would have attained $2.6 \mathrm{~W} / \mathrm{m} 2$

$189,4.5 \mathrm{~W} / \mathrm{m} 2,6.0 \mathrm{~W} / \mathrm{m} 2$, and $8.5 \mathrm{~W} / \mathrm{m} 2$ over the value in the preindustrial period (Taylor et al. 2012 ,

190 Rogelj et al. 2012, Stocker et al. 2013). The data used was produced by interpolation of data

191 predictions for 2060 and 2080 to produce an estimate of climate condition for the year 2070.

192 Cross correlation among 19 bioclimatic variables and two independent variables was checked to

193 avoid the presence of redundant variables in the model. The input rate of the variables was 
194 calculated by Jackknife test of Maxent model, and IBM-SPSS statistical software (Statistical

195 Product and Service Solutions, Version 20.0, SPSS Inc., Chicago, IL, USA) was used for Pearson's

196 correlation. From each highly correlated pair of variables, one variable was removed $(>|0.8|)$ and

197 the ones with high contribution rate were chosen (Liu et al. 2005).

\section{$198 \quad$ 2.6 Climatic niche Modeling}

199 We

used

Maxent

Version

200 (https://www.biodiversityinformatics.amnh.org/open source/Maxent, (Phillips et al. 2006)) to

201 predict the current and future potential distribution of teff. Species distribution point data was

202 stored in csv file format and included coordinate data such as name, latitude and longitude of the

203 species. ArcGIS 10.5 converted all environmental variables to ASCII raster grids and species

204 presence coordinates to decimal degrees. Certain settings (500 iterations, 0.00001 convergence

205 requirement, 10,000 peak context points) were kept by default. The software ran with $75 \%$ of

206 presence locations and tested the efficiency of the model with the remaining $25 \%$ of the presence

207 points (Phillips et al. 2006, Phillips \& Dudík 2008). In Phillips et al. (2006), a detailed

208 mathematical description of Maxent was mentioned.

209 A continuous probabilistic layer ranging from 0 to 1 is the output of the model. Higher-value areas

210 indicate more desirable conditions for growth of species (Phillips et al. 2006). For each case, we

211 selected the minimum performance by training presence (MTP) as a threshold or "cut-off" value

212 (Hijmans \& Graham 2006). The MTP can be interpreted ecologically to include those cells that

213 are expected to be at least as sufficient as those where the species has been defined as present. We

214 have categorized four habitat suitability groups, unsuitable, low suitability, moderate suitability,

215 and high suitability by Spatial Analyst tool in ArcMap 10.5, so as to measure the niche centroid 216 from present to future climate change scenarios. 
217 There are two ratification processes in the Maxent model: area under the curve (AUC) and

218 Jackknife. Area Under the Curve (AUC) of Receiver Operating Characteristic (ROC) curves was

219 used to verify the suitability of teff estimated by the model. The AUC represents the probability

220 that a randomly chosen teff occurrence exceeds that of randomly choosing an absence. The AUC

221 values lie between 0.5 and 1.0 (perfect prediction), and can be divided into five categories:

222 outstanding $(>0.9)$, good $(0.8-0.9)$, approved $(0.7-0.8)$, poor $(0.6-0.7)$ and invalid $(<0.6)($ Elith

223 2006, Suwannatrai et al. 2017).

224 Jackknife is part of Maxent model and it is calibrated with all permutations of the groups using

225 occurrence points and background data from $k-1$ spatial groups and then evaluated with the

226 withheld and alternate estimates of which variables are most important in the model (Hu et al.

227 2011). Variables that significantly affected the model were identified and chosen based on percent 228 contribution to the model.

\section{Results}

\subsection{Variable Contribution Analysis}

232 After testing for independence between climatic variables, the ones with low predictive power or high similarities to other variables in prediction were identified. Eleven variables (11) were

234 selected for the model according to the contribution rate of each variable (Table 1). The potential 235 teff distribution under current projected climate change was mostly affected by the mean 236 temperature of the coldest season (Biol1 78.3\%) and precipitation seasonality (Bio15 8.3\%)

237 (Table 1). The potential teff distribution under the RCP scenarios was also influenced mainly by 238 Biol1 (77.8\%-80.4\%), Bio15 (7.3\%-9.04\%). The Pearson's correlation coefficients are included 239 in the supplementary material (Table S1). 
Table 1. Percent contributions of the climate variables for teff distribution in the MaxEnt model.

243 The jackknife test indicated that the bioclimatic variables Bio11, Bio14, Bio19, and Bio4 provided

244 huge gains when they were used independently to estimate potential teff distribution under current

245 conditions and under RCP scenarios 2.6 to 6.0 (Figure 4). The potential distribution of the species

246 under the RCP8.5 scenario was most strongly associated with Bio11 (gain, 0.59), Bio2 (gain, 0.12),

247 Bio19 (gain, 0.15) and Bio4 (gain, 0.13), respectively (Figure 4E).

248

Figure 4 Jackknife test variable contributions to the potential distribution of teff distribution under: (A) current climate condition scenario, (B) RCP 2.6 scenario, (C) RCP 4.5 scenario, (D) RCP 6.0 scenario, and (E) RCP 8.5 scenario. The regularized training gain describes how much better the simulated distribution fits the present data compared to a uniform distribution. The dark blue bars indicate the gain from using each variable in isolation, the light blue bars indicate the gain lost by removing the single variable from the full model, and the red bar indicates the gain using all the variables.

The response curves indicate the relationship between environmental variables and habitat suitability and can provide information on teff ecological niche. The ranges of suitability for environmental variables were identified by the threshold of normal suitable habitats. The response curves of 8 variables of teff habitat suitability are illustrated in Figure 5, as is the suitable range for each variable. The highest suitability areas for teff have a mean temperature of the coldest season (Bio11) between 14-19 ${ }^{\circ} \mathrm{C}$, an annual precipitation seasonality (Bio15) between $60 \%$ to $122 \%$, precipitation of the coldest season (Bio19) between $8.5-110 \mathrm{~mm}$, a slope between 0 to $3^{\circ}$, a temperature annual range (Bio7, Bio5-Bio6) from 11.8 to $26.6{ }^{\circ} \mathrm{C}$, a temperature seasonality 
264 (standard deviation $\times 100$, Bio4) from 1000-1550, precipitation of the driest period (Bio14) from

$2650.3 \mathrm{~mm}$ to $20 \mathrm{~mm}$, an isothermality (Bio3) above 68 and an aspect from $355^{\circ}$ to $0^{\circ}$ (Figure 5).

266

267

268

269

270

Figure 5 Response curves of 8 environmental variables in the teff habitat distribution model. A:Bio11( Mean temperature of coldest season $\left({ }^{\circ} \mathrm{C}^{*} 10\right)$ ); B: Bio15( Precipitation seasonality (CV)); C: Bio7( Temperature annual range (Bio5-Bio6));D: Bio19( Precipitation of coldest season $\left.\left(\mathrm{mm}^{*} 10\right)\right)$; E:Bio14( Precipitation of driest period $\left.\left(\mathrm{mm}^{*} 10\right)\right)$; F:Bio3( Isothermality $($ Bio2/Bio7 $\times 100))$;G:Bio4 ( Temperature seasonality (standard deviation $\left.\times 100)\left({ }^{\circ} \mathrm{C}^{*} 10\right)\right) ; \mathrm{H}($ Slope

\section{$271 \quad 3.2$ Performance and accuracy of the Maxent Model}

272 Of the climatic variables, mean temperature of the coldest quarter played the greatest role in the

273 model in both percent contribution and permutation importance, which reflects the effect of a

274 variable determined by impact to the model when the variable is absent (Table 2). However, in the

275 variable analysis, mean temperature of the coldest quarter was not independent of mean

276 temperature of the warmest quarter, or mean temperature of the driest quarter. Therefore,

277 temperature generally had the greatest effect, especially during the growing season, which would

278 logically be the highest for teff.

279 AUC values were above 0.829 under current and four projected climate scenarios (Table 3 ).

280 According to the performance classification standard, prediction accuracy was very good, as AUC

281 for training and testing were 0.84 and 0.83 , respectively.

282

Table 2. Estimates of relative contributions and permutation importance of the predictor environmental variables to the Maxent model.

Table 3. Results of receiver operating characteristic (ROC) analysis under current climate and four future projected scenarios. 
289 3.3. Predicted distribution of teff under current climate condition and future scenarios

290 The model showed that teff has a climatically suitable area of minimum annual precipitation

291 between 550 and $1770 \mathrm{~mm}$. The minimum mean temperature is expected to be $14.9{ }^{\circ} \mathrm{C}$ with

292 maximum values of $26.75{ }^{\circ} \mathrm{C}$ in Ethiopia. The model showed that under such temperature

293 conditions, suitable distribution classes under the current and future scenarios showed that the

294 warmer the climate condition, there will be a greater shift from high-level to low-level suitability.

295 The distribution classes under current and future scenarios show that teff in Ethiopia is highly

296 suitable in the central region of the country. Areas with higher temperature that do not correlate

297 with suitable teff habitat lie on the eastern side of highlands and those that do not correlate with

298 higher temperature lie in the western lowlands (Figure 6).

299 Generally, teff simulated distribution includes the west part of Ethiopia in current and future

300 climate condition (Fig.7). The high suitable area lies in the northwest part of the country, related

301 to low temperature and high precipitation (Fig.6). There is no distribution of teff in the eastern part

302 of Ethiopia related to low altitude, high temperature and low precipitation (Fig.6).

303

304

Figure 6 Average annual rainfall (A) and average annual temperature (B) in Ethiopia over three decades.

\subsection{Teff Habitat Suitability under current and future scenarios}

306 Under current climate, the distribution area with low suitability summed up 463,453 $\mathrm{km}^{2}$, moderate

307 suitability $296,933 \mathrm{~km}^{2}$, and with high suitability, $14,513 \mathrm{~km}^{2}$, giving a total suitable area of $58 \%$

308 of our research area. Considering the four projection scenarios, the total suitable area declined with

309 climate warming in RCP $4.5\left(770,139 \mathrm{~km}^{2}\right)$ and RCP $8.5\left(767,554 \mathrm{~km}^{2}\right)$ while in other scenarios

310 suitable area increased (Table 4, Figure 7). A difference was found between the current suitable

311 area and the predicted habitat in RCP 2.6 and 6.0 (Figure 7). In particular, the area of suitable teff 
312 habitat increased in both RCP 2.6 and 6.0 while it decreased in RCP $4.5\left(-4760 \mathrm{~km}^{2}\right)$ and RCP 8.5

$313\left(-7345 \mathrm{~km}^{2}\right)$ (Table 4).

314

315

316

317

318 Suitable habitat including moderately and highly suitable areas remained roughly the same in each 319

320

321

322

323

324

325

326

327

328

329

330

331

332

333

334

335

336
Figure 7 Distribution of unsuitable, and low, moderate, and highly suitable teff habitats based on current and future distribution under four climate scenarios (Note: A: current; B: RCP 2.6; C: RCP4.5; D: RCP6.0; E: RCP8.5) future scenario (from 0.042 to 0.052 for RCP2.6 and 8.5 respectively). Taking the ratio of moderately suitable habitat to low suitable habitat, the largest projected deviation was under the RCP 4.5 scenario (ratio=0.74 vs. $0.64-0.67$ for the other RCPs), resulting in a relative decrease of low suitable area and an increase of moderate suitability. In the other scenarios, the model predicted a slight increase of highly suitable and a decrease of moderately suitable area (Table 4).

Table 4. Total area of suitable and unsuitable teff habitats based on current distribution data and projected four future climate scenarios.

Unsuitable area in the future decreases in RCP 2.6 and RCP 6.0 compared to the current situation while it increases in RCP4.5 and RCP 8.5. Also, low suitability areas decrease in RCP 2.6, RCP 4.5 and RCP 8.5 while increasing in the RCP 6.0 scenario. Moderate suitability areas increase in RCP 2.6, RCP 4.5 and RCP 6.0 but decline in RCP 8.5. Again, high suitability areas compared with the current situation increase in area in RCP 4.5, RCP 6.0 and RCP 8.5 but not in the RCP 2.6 scenario (Table 4$)$.

On the regional scale, the largest projected shifts in habitat suitability occur in the northwest region of the country under the most extreme radiative forcing case of RCP 8.5, where a patch of currently unsuitable area becomes moderately suitable (Figure 7). Despite this single projected increase in 
337 area, overall, suitable land area is expected to decrease under RCP 4.5 and RCP 8.5, including a

338 decrease in total moderately suitable land. The result of a shift in suitable land towards the west 339 and away from the east contrasts with the path of rainclouds traveling from west to east.

\section{4. Discussion}

342 Ultimately, several studies and our own research results show it is necessary to assess the impact

343 of climate change on teff distribution and take it into account in adaptive management policies in

344 order to minimize the impact of climate change.

345 Recent research findings indicate that most updated climate projections of GCM (global climate

346 model) used in the IPCC Fifth Assessment Report were used to forecast the effect of climate

347 change on teff that was used for crop suitability (Alemayehu et al 2020). The distribution of plants

348 would be significantly affected by climate change according to the findings of several researchers.

349 For example: McSweeney et al., 2010a and Niang et al.,2014, reported that increased temperature

350 and precipitation was projected in East Africa. This had an impact by decreasing the yield of many

351 cereals by shortening the growing season length, amplifying water stress and increasing incidence

352 of weed outbreak and diseases. As (Prasad et al., 2008; Nelson et al., 2009 and Thornton et al.,

353 2009) indicated that for high altitude regions in Ethiopia, such as mountainous land where

354 temperature is the limiting factor for plant growth, a rise in temperature will possibly increase crop

355 yield, but that in lowland areas, it will increase the risk of water stress. They also indicated that

356 precipitation variability due to various effects of climate change, and the resulting heat and water

357 stress, are considered the most important factors. (Elith and Graham,2009) also reported that there

358 is always uncertainty about selecting the best fit methods to model species distributions, as

359 different models and methods change the result of the predictions under different scenarios due to 
360 various mechanisms. While there remains considerable uncertainty as to the extent and pace of

361 global warming trends and their impact on plant species, preceding researchers have pointed out

362 that climate change has a significant impact on the distributions of the different species by causing

363 shifts, even contractions in species ranges, and change of terrestrial ecosystems function (Barbet

364 et al., 2012; Li et al.,2015 and Petitpierre et al.,2016). Considerable effort was made to expand the

365 collection and increase the number of species studied. Due to limiting factors, such as climatic and

366 environmental conditions, difficulty accessing some of the data and time constraints during

367 occurrence sampling, some locations that were unreachable may have been overlooked. This

368 shortcoming is believed to have slightly affected our results; hence, future studies should more

369 comprehensively focus on the climate factor and other variables such as soil organic carbon, clay,

370 bulk density (BD), Elevation, and $\mathrm{pH}$. In future research, we should consider these methods to

371 improve the accuracy of the predictors.

372 Ethiopia is predicted to be highly vulnerable to climate change, manifesting an increased warming

373 accompanied by inconsistent rainfall (Conway \& Schipper 2011). In that direction, potential teff

374 distribution under current conditions and projected climate change scenarios was mostly affected

375 by the temperature and precipitation. Evangelista et al. (2013) found that teff distribution depended

376 most on precipitation variables, especially precipitation of the wettest quarter. However, we have

377 found that the potential teff distribution was mostly affected by mean temperature of coldest

378 quarter (Bio11), precipitation seasonality (Bio15) and precipitation of coldest quarter (Bio19).

379 As reported by Tan et al 2016, due to increasing temperature and varying rainfall the areas suitable

380 for cultivating teff will become centralized to the plateau of Ethiopia in the future. Yet, (Gregory

381 et al., 2005, Turner and Rao, 2013) suggest that for most of the crops, including teff, suitability

382 decreased due to the warming trend of climate change. Furthermore, Thornton et al., 2009 state 
383 that if temperature increases above the level suitable for a crop then it will lead to the death of that

384 crop. Teff is known to be a primary cereal, which is less tolerant of cold (Chamberlin and Schmidt,

385 2012; Yumbya et al.,2014, Sen et al.,2016). Though our model share some common data and

386 methods with preceding studies, it has arrived at different findings because it uses a wider range

387 of data and environmental variables than those earlier studies. Existing research of different

388 regions has reported variables found to have an important effect on various species. For example:

389 Evangelista et al., 2013 Studied teff by using three climate projection model that the value of

390 predictable were 0.79 (Bio16, Bio12,Bio19,Bio15) and others studied different species in different

391 geographical area including ,Elham et al.,2015 (Bio2, Bio3, Bio7, Bio8, Bio13, Bio14, Bio15,

392 Bio18), Ardestani et al.,2015 (Bio8, Bio19 ,Bio2 ,Bio13 ,Bio7), Sen et.,2016 (Bio4 and Bio19),

393 Rong et.,2019 (Bio1, Bio8 and elevation), Abdelaal et al.,2020 (elevation, precipitation,

394 temperature and soil), and Yang et.,2020 (Temp Seasonality, Precipitation, Vegetation Type, Soil

395 Type). Our results indicate that temperature of coldest quarter had a predictability value of 0.83

396 for teff, which is stronger than that of any other existing model. Mean temperature of coldest

397 quarter (Bio11), Precipitation seasonality (Bio15), Precipitation of coldest quarter (Bio19), Slope,

398 and Temperature annual range (Bio7) were the variables with the greatest effect on teff

399 distribution.

400 Our result indicates that the suitable and unsuitable area somehow varies, increasing and 401 decreasing under four climate change scenarios (i.e., RCP2.6, RCP4.5, RCP6.0 and RCP8.5).

402 Comparing unsuitable area in current condition with that in scenario RCP 2.6 and RCP 6.0, 403 unsuitable area decreased by 11058 and $16186 \mathrm{~km}^{2}$ respectively. Also, the RCP 4.5, RCP 8.5

404 decreased by 4760 , and $7345 \mathrm{~km}^{2}$ respectively. Suitability area decreased comparing the current 405 condition with RCP 8.5, suitability area increased comparing RCP 8.5 with the other three 
406 scenarios due to different climate changes under four scenarios. Future climate change scenarios

407 RCP 2.6 and RCP 6.0 provided the most favorable outcomes in terms of loss of suitable teff habitat.

408 However, RCP 2.6 resulted in a greater loss of high suitable habitat, whereas projections from

409 RCP 6.0 show the highest preservation of total potential crop area. Surprisingly, projected loss of

410 suitable habitat did not correlate with increasing projected radiative forcing. Alemayehu et al

411 (2018), in relation to future climate change from 2050-2070s, indicated that generally suitable area

412 for teff under climate change scenarios will suffer a slight increase in almost all administrative

413 regions of Ethiopia. This increase in suitability will transform marginalized currently unsuitable

414 areas to suitable area for teff under climate change scenarios. An example of these areas are Afar

415 and Somali regional states which have low precipitation and high temperature conditions, and are

416 predicted to have increased precipitation and higher temperatures. In contrast with our results in

417 the four scenarios, they demonstrate the possible future expansion of the cultivation of teff in the

418 east lowlands of Ethiopia. In 2050, the area expects a temperature range between $15^{\circ} \mathrm{C}$ and $27^{\circ} \mathrm{C}$,

419 and a compensating increase in rainfall between 600 and $1900 \mathrm{~mm}$ where teff would be

420 climatically suitable (Yumbya 2014). Several studies indicate that changes in rainfall, temperature

421 and seasonality in Ethiopia directly affect rainfed agriculture (Evangelista et al. 2013; Gebre et al.

422 2013; Asfaw et al. 2018; Alemayehu \& Bewket 2017; Worku et al. 2019). Evangelista et al. (2013)

423 predicted a $350,000 \mathrm{~km}^{2}$ loss of suitable crop area by 2050, however, in our study, areas of crop

424 suitability showed different trends in the future climate change scenarios. In the model used by

425 Evangelista et al. (2013) rainfall was the primary climate driver (and not coupled with mean

426 temperature of the coldest season), so the model outcomes were heavily dependent on the specific

427 rainfall predictions of the climate data. The main difference in the models lies in the confidence of

428 an environmental variable versus the prediction of a climatic variable. 
429 Most studies using models to predict the climate change in Ethiopia revealed that important climate 430 variables influence teff distribution. The contribution rates of precipitation of wettest quarter 431 (Bio16), annual precipitation (Bio12), precipitation of the coldest quarter (Bio19), and 432 precipitation seasonality (Bio15) are 26.6, 9.3, 8.3, and 6.1\%, respectively (Evangelista et al. 433 2013). By contrast, our analysis results show that contribution rates of four environmental 434 variables (Bio11, Bio15, Bio19, and slope) are 78.3, 8.3, 3.7, $3.3 \%$ respectively suggesting that 435 precipitation in the wettest quarter is even more important than previously thought.

436 Our model provided reasonably strong AUC predictions on the geographic changes in teff 437 suitability throughout Ethiopia under projected climate change. Several studies reveal that all models have associated assumptions and extrapolation modes in time or space, and are subject to violating assumptions of species distribution models (Wiens et al. 2009). We used a Maxent model to show current teff distribution and to predict future climate impacts on it. Since the model relies on predicted future climate scenarios, an amount of uncertainty is added. We should have considered including management, soil and other teff varieties which are grown in Ethiopia in our model analysis. We strongly believe that our research could be improved by including 444 management of farming practice and preparation for teff harvesting components, but we believe that lack of soil and other data in our analysis did not significantly affect the results.

446 Climate change affects the teff crop both in current and future scenarios. Results indicate that the 447 differing future distributions are not uniformly affected by predicted changes in climate. Moreover, 448 the predicted future damage is so severe that the survival of the Ethiopian agricultural sector, will 449 be at stake unless adaptive policies are implemented. As Ethiopia, many other East African 450 countries are facing the erratic effects of climate change with the same projections (Deressa \& 451 Hassan 2009; Di Falco \& Veronesi 2013). 


\section{5. Conclusions}

453 Our work presents an opportunity for the agricultural sector, modelers and policy makers to 454 examine the effect of climate change on teff so as to minimize negative impacts. Our result 455 revealed that four environmental factors have an important influence on teff distribution, namely 456 Mean temperature of coldest quarter (Bio11), Precipitation seasonality (Bio15), Precipitation of 457 coldest quarter (Bio19), Slope, and Temperature annual range (Bio7). Furthermore, based on 458 current and future climate future scenarios conditions, we found out that for teff distribution in

459 western Ethiopia the high suitable area lies on the northwest part of the county. We discovered 460 climate change is happening and influencing the teff distribution, with a total projected loss 5000$4617300 \mathrm{~km}^{2}$ of suitable habitat. While this change does not pose substantial threat on the short term, 462 on the long term it may have a significant impact on the future availability to grow teff as staple 463 crop in Ethiopia.

\section{Author Attribution}

465 Dinka Zewudie wrote the paper, prepared figures and tables, reviewed drafts of the paper.

466 Wenguang Ding reviewed drafts of the paper.

467 Chuanyan Zhao conceived and designed the experiments.

468 Zhanlei Rong and Yapeng Chang analyzed the data.

ADDITIONAL INFORMATION AND DECLARATIONS

471 Funding

472 Supported by the Strategic Priority Research Program of Chinese Academy of Sciences Grant No. $473 \quad$ XDA20100102

474 Conflict of Interest 
475 The authors declare there are no competing interests

476

477

478

479

480

481

482

483

484

485

486

487

488

489

490

491

492

493

494

495

496

497

498

499

500

501

502

503

504

505

506

507

508

509

510

511

512

Acknowledge: We thank people who help in the manuscript, and foundation support.

\section{References}

Abdelaal, M., Fois, M., Dakhil, M. A., Bacchetta, G., \& El-Sherbeny, G. A. (2020). Predicting the Potential Current and Future Distribution of the Endangered Endemic Vascular Plant Primula boveana Decne. ex Duby in Egypt. Plants, 9(8), 957.

Alberto, F. J., Aitken, S. N., Alía, R., González-Martínez, S. C., Hänninen, H., Kremer, A., ... \& Savolainen, O. (2013). Potential for evolutionary responses to climate change-evidence from tree populations. Global Change Biology, 19(6), 1645-1661.

Alemayehu N., Masafu M., Ebro A., Tegegne A., Gebru G. (2018) Climate Change and Variability in the Mixed Crop/Livestock Production Systems of Central Ethiopian Highland. In: Leal Filho W. (eds) Handbook of Climate Change Resilience. Springer, Cham. https://doi.org/10.1007/978-3-319-71025-9_120-1

Alemayehu N., Masafu M., Ebro A., Tegegne A., Gebru G. (2020) Climate Change and Variability in the Mixed Crop/Livestock Production Systems of Central Ethiopian Highland. In: Leal Filho W. (eds) Handbook of Climate Change Resilience. Springer, Cham. https://doi.org/10.1007/978-3-31993336-8_120

Alemayehu, A., \& Bewket, W. (2017). Local spatiotemporal variability and trends in rainfall and temperature in the central highlands of Ethiopia. Geografiska Annaler: Series A, Physical Geography, 99(2), 85-101.

Anderson, R. P., Lew, D., \& Peterson, A. T. (2003). Evaluating predictive models of species' distributions: criteria for selecting optimal models. Ecological modelling, 162(3), 211232.

Ardestani, E. G., Tarkesh, M., Bassiri, M., \& Vahabi, M. R. (2015). Potential habitat modeling for reintroduction of three native plant species in central Iran. Journal of arid land, 7(3), 381-390.

Asfaw, A., Simane, B., Hassen, A., \& Bantider, A. (2018). Variability and time series trend analysis of rainfall and temperature in northcentral Ethiopia: A case study in Woleka subbasin. Weather and Climate Extremes, 19, 29-41.

Assefa, K., Tefera, H., Merker, A., Kefyalew, T., \& Hundera, F. (2001). Quantitative trait diversity in tef [Eragrostis tef (Zucc.) Trotter] germplasm from Central and Northern Ethiopia. Genetic Resources and Crop Evolution, 48(1), 53-61.

Barbet-Massin, M., Jiguet, F., Albert, C. H., \& Thuiller, W. (2012). Selecting pseudo-absences for species distribution models: how, where and how many?. Methods in ecology and evolution, 3(2), 327-338. 
513 Barnett, T. P., Hegerl, G., Knutson, T., \& Tett, S. (2000). Uncertainty levels in predicted patterns

514

515

516

517

518

519

520

521

522

523

524

525

526

527

528

529

530

531

532

533

534

535

536

537

538

539

540

541

542

543

544

545

546

547

548

549

550

551

552

553

554

555

556 of anthropogenic climate change. Journal of Geophysical Research: Atmospheres, 105(D12), 15525-15542.

Beltramino, A. A., Vogler, R. E., Gregoric, D. E. G., \& Rumi, A. (2015). Impact of climate change on the distribution of a giant land snail from South America: predicting future trends for setting conservation priorities on native malacofauna. Climatic Change, 131(4), 621-633.

Bertrand, R., Lenoir, J., Piedallu, C., Riofrio-Dillon, G., de Ruffray, P., Vidal, C., ... \& Gégout, J. C. 2011. Changes in plant community composition lag behind climate warming in lowland forests. Nature, 479(7374), 517-520.

Betts, R. A., Collins, M., Hemming, D. L., Jones, C. D., Lowe, J. A., \& Sanderson, M. G. 2011. When could global warming reach 4 C?. Philosophical Transactions of the Royal Society A: Mathematical, Physical and Engineering Sciences, 369(1934), 67-84.

Brown, J. L. (2014). SDM toolbox: a python-based GIS toolkit for landscape genetic, biogeographic and species distribution model analyses. Methods in Ecology and Evolution, 5(7), 694-700.

Caminade, C., Medlock, J. M., Ducheyne, E., McIntyre, K. M., Leach, S., Baylis, M., \& Morse, A. P. (2012). Suitability of European climate for the Asian tiger mosquito Aedes albopictus: recent trends and future scenarios. Journal of the Royal Society Interface, $9(75), 2708-2717$.

Chamberlin, J., \& Schmidt, E. (2012). Ethiopian agriculture: A dynamic geographic perspective. Food and agriculture in Ethiopia: progress and policy challenges, 21-52.

Cheng, A., Mayes, S., Dalle, G., Demissew, S., \& Massawe, F. (2017). Diversifying crops for food and nutrition security-a case of teff. Biological Reviews, 92(1), 188-198.

Conway, D., \& Schipper, E. L. F. (2011). Adaptation to climate change in Africa: Challenges and opportunities identified from Ethiopia. Global Environmental Change, 21(1), 227237.

Cowie, A. L., Orr, B. J., Sanchez, V. M. C., Chasek, P., Crossman, N. D., Erlewein, A., ... \& Tengberg, A. E. (2018). Land in balance: The scientific conceptual framework for Land Degradation Neutrality. Environmental Science \& Policy, 79, 25-35.

CSA. (2014). Agricultural Sample Survey for 2013/14. Statistical Bulletin 532. Addis Ababa, Ethiopia: Central Statistical Agency

Deressa, T. T., \& Hassan, R. M. (2009). Economic impact of climate change on crop production in Ethiopia: Evidence from cross-section measures. Journal of African economies, 18(4), 529-554.

Di Falco, S., \& Veronesi, M. (2013). How can African agriculture adapt to climate change? A counterfactual analysis from Ethiopia. Land Economics, 89(4), 743-766.

Dinar A (2007) Climate change: the final blow for agriculture in Africa? Research Brief.The World Bank, Washington

Dinku, T., Connor, S. J., Ceccato, P., \& Ropelewski, C. F. (2008). Comparison of global gridded precipitation products over a mountainous region of Africa. International Journal of Climatology: A Journal of the Royal Meteorological Society, 28(12), 1627-1638.

Elith J, Phillips SJ, Hastie T, Dudík M, Chee YE, Yates CJ. 2011. A statistical explanation of MaxEnt for ecologists. Diversity and distributions 17:43-57. 
557

558

559

560

561

562

563

564

565

566

567

568

569

570

571

572

573

574

575

576

577

578

579

580

581

582

583

584

585

586

587

588

589

590

591

592

593

594

595

596

597

598

599

600

Elith, J., H. Graham, C., P. Anderson, R., Dudík, M., Ferrier, S., Guisan, A., ... \& Li, J. (2006). Novel methods improve prediction of species' distributions from occurrence data. Ecography, 29(2), 129-151.

Evangelista P, Young N, and Burnett J. 2013. How will climate change spatially affect agriculture production in Ethiopia? Case studies of important cereal crops. Climatic Change 119:855-873. 10.1007/s10584-013-0776-6

Fazzini M, Bisci C, Billi P. 2015. The Climate of Ethiopia. In book: Landscapes and Landforms of Ethiopia (pp.23) Ed: World Geomorphological Landscapes. Springer Verlag. Editors: Billi P. doi: 10.1007/978-94-017-8026-1_3

Fick, S. E., \& Hijmans, R. J. (2017). WorldClim 2: new 1-km spatial resolution climate surfaces for global land areas. International journal of climatology, 37(12), 4302-4315.

Funk, V. A., \& Richardson, K. S. (2002). Systematic data in biodiversity studies: use it or lose it. Systematic biology, 51(2), 303-316.

Gebre, H., Kindie, T., Girma, M., \& Belay, K. (2013). Trend and variability of rainfall in Tigray, northern Ethiopia: analysis of meteorological data and farmers' perception. Academia Journal of Agricultural Research, 1(6), 088-100.

Gebrechorkos, S. H., Hülsmann, S., \& Bernhofer, C. (2019). Long-term trends in rainfall and temperature using high-resolution climate datasets in East Africa. Scientific Reports, 9(1), $1-9$.

Gebrehiwot, T., \& Van Der Veen, A. (2013). Farm level adaptation to climate change: the case of farmer's in the Ethiopian Highlands. Environmental management, 52(1), 29-44.

Gissila, T., E.Black, D. I. F.Grimes, and J. M.Slingo, (2004): Seasonal forecasting of the Ethiopian summer rains.Int. J. Climatol., 24, 1345-1358.

Gleixner, S., Keenlyside, N., Viste, E., \& Korecha, D. (2017). The El Niño effect on Ethiopian summer rainfall. Climate Dynamics, 49(5-6), 1865-1883.

Graham, C. H., \& Hijmans, R. J. (2006). A comparison of methods for mapping species ranges and species richness. Global Ecology and biogeography, 15(6), 578-587.

Gregory, P. J., Ingram, J. S., \& Brklacich, M. (2005). Climate change and food security. Philosophical Transactions of the Royal Society B: Biological Sciences, 360(1463), 2139-2148.

Guo Y, Li X, Zhao Z, Wei H, Gao B, and Gu W. 2017a. Prediction of the potential geographic distribution of the ectomycorrhizal mushroom Tricholoma matsutake under multiple climate change scenarios. Scientific Reports 7. 10.1038/srep46221

Guo Y, Wei H, Lu C, Gao B, and Gu W. 2016. Predictions of potential geographical distribution and quality of Schisandra sphenanthera under climate change. PeerJ 4:e2554. 10.7717/peerj.2554

Guo, Y., Li, X., Zhao, Z., Wei, H., Gao, B., \& Gu, W. (2017). Prediction of the potential geographic distribution of the ectomycorrhizal mushroom Tricholoma matsutake under multiple climate change scenarios. Scientific reports, 7, 46221.

Hansen, J., Ruedy, R., Sato, M., \& Lo, K. (2010). Global surface temperature change. Reviews of Geophysics, 48(4).

Hansen, J., Sato, M., Ruedy, R., Lo, K., Lea, D. W., \& Medina-Elizade, M. (2006). Global temperature change. Proceedings of the National Academy of Sciences, 103(39), 1428814293. 
601

602

603

604

605

606

607

608

609

610

611

612

613

614

615

616

617

618

619

620

621

622

623

624

625

626

627

628

629

630

631

632

633

634

635

636

637

638

639

640

641

642

643

644

645

646

647

Hijmans, R. J., \& Graham, C. H. (2006). The ability of climate envelope models to predict the effect of climate change on species distributions. Global change biology, 12(12), 22722281.

Hordofa, T. \& Menkir, Michael \& Awulachew, Seleshi Bekele \& Erkossa, T. (2008). "Irrigation and rain-fed crop production system in Ethiopia," Conference Papers h044065, International Water Management Institute.

Hu, J., \& Jiang, Z. (2011). Climate change hastens the conservation urgency of an endangered ungulate. PloS one, 6(8), e22873.

Intergovernmental Panel on Climate Change. (2007). Climate Change 2007 - Mitigation of Climate Change: Working Group III contribution to the Fourth Assessment Report of the IPCC. Cambridge: Cambridge University Press. doi:10.1017/CBO9780511546013.

IPCC, 2013: Climate Change 2013: The Physical Science Basis. Contribution of Working Group I to the Fifth Assessment Report of the Intergovernmental Panel on Climate Change [Stocker, T.F., D. Qin, G.-K. Plattner, M. Tignor, S.K. Allen, J. Boschung, A. Nauels, Y. Xia, V. Bex and P.M. Midgley (eds.)]. Cambridge University Press, Cambridge, United Kingdom and New York, NY, USA, $1535 \mathrm{pp}$.

James, R., \& Washington, R. (2013). Changes in African temperature and precipitation associated with degrees of global warming. Climatic change, 117(4), 859-872.

Joshi, M., Hawkins, E., Sutton, R., Lowe, J., \& Frame, D. 2011. Projections of when temperature change will exceed $2 \mathrm{C}$ above pre-industrial levels. Nature Climate Change, 1(8), 407412.

Kamali, B., Abbaspour, K. C., Lehmann, A., Wehrli, B., \& Yang, H. (2018). Spatial assessment of maize physical drought vulnerability in sub-Saharan Africa: Linking drought exposure with crop failure. Environmental Research Letters, 13(7), 074010.

Kamilar, J. M., \& Beaudrot, L. (2013). Understanding primate communities: Recent developments and future directions. Evolutionary Anthropology: Issues, News, and Reviews, 22(4), 174-185.

Korecha, D., \& Barnston, A. G. (2007). Predictability of june-september rainfall in Ethiopia. Monthly weather review, 135(2), 628-650.

Kumar, P. (2012). Assessment of impact of climate change on Rhododendrons in Sikkim Himalayas using Maxent modelling: limitations and challenges. Biodiversity and Conservation, 21(5), 1251-1266.

Kumar, S., \& Stohlgren, T. J. (2009). Maxent modeling for predicting suitable habitat for threatened and endangered tree Canacomyrica monticola in New Caledonia. Journal of Ecology and the Natural Environment, 1(4), 094-098.

Kumar, S., Spaulding, S. A., Stohlgren, T. J., Hermann, K. A., Schmidt, T. S., \& Bahls, L. L. (2009). Potential habitat distribution for the freshwater diatom Didymosphenia geminata in the continental US. Frontiers in Ecology and the Environment, 7(8), 415-420.

Ledig, F. T., Rehfeldt, G. E., Sáenz-Romero, C., \& Flores-López, C. (2010). Projections of suitable habitat for rare species under global warming scenarios. American journal of botany, 97(6), 970-987.

Lenoir J, Gégout JC, Marquet PA, de Ruffray P, Brisse H. A significant upward shift in plant species optimum elevation during the 20th century. Science. 2008 Jun 27;320(5884):1768-71. doi: 10.1126/science.1156831. PMID: 18583610.

Li, R., Xu, M., Wong, M. H. G., Qiu, S., Sheng, Q., Li, X., \& Song, Z. (2015). Climate change-induced decline in bamboo habitats and species diversity: Implications for giant panda conservation. Diversity and Distributions, 21(4), 379-391.

Peer) reviewing PDF | (2020:07:50911:2:1:NEW 8 Jan 2021) 
648

649

650

651

652

653

654

655

656

657

658

659

660

661

662

663

664

665

666

667

668

669

670

671

672

673

674

675

676

677

678

679

680

681

682

683

684

685

686

687

688

689

690

Liao, H., \& Chang, W. (2014). Integrated assessment of air quality and climate change for policy-making: highlights of IPCC AR5 and research challenges. National Science Review, 1(2), 176-179.

Liu, C., Berry, P. M., Dawson, T. P., \& Pearson, R. G. (2005). Selecting thresholds of occurrence in the prediction of species distributions. Ecography, 28(3), 385-393.

Mcsweeney, C., New, M., Lizcano, G., \& Lu, X. (2010). The UNDP Climate Change Country Profiles: Improving the accessibility of observed and projected climate information for studies of climate change in developing countries. Bulletin of the American Meteorological society, 91(2), 157-166.

Minten, B., Tamru, S., Engida, E., \& Kuma, T. (2016). Feeding Africa's cities: The case of the supply chain of teff to Addis Ababa. Economic Development and Cultural Change, 64(2), 265-297.

Nelson, G. C., Rosegrant, M. W., Koo, J., Robertson, R., Sulser, T., Zhu, T., ... \& Magalhaes, M. (2009). Climate change: Impact on agriculture and costs of adaptation (Vol. 21). Intl Food Policy Res Inst.

Niang, I., Ruppel, O. C., Abdrabo, M. A., Essel, A., Lennard, C., Padgham, J., \& Urquhart, P. (2014). Africa. Part B: Regional Aspects. Contribution of Working Group II to the Fifth Assessment Report of the Intergovernmental Panel on Climate Change. Climate Change.

Pachauri, R. K., Allen, M. R., Barros, V. R., Broome, J., Cramer, W., Christ, R., ... \& Dubash, N. K. (2014). Climate change 2014: synthesis report. Contribution of Working Groups I, II and III to the fifth assessment report of the Intergovernmental Panel on Climate Change (p. 151). Ipcc.

Parmesan, C., \& Yohe, G. 2003. A globally coherent fingerprint of climate change impacts across natural systems. Nature, 421(6918), 37-42.

Peterson, A. T. (2006). Ecologic niche modeling and spatial patterns of disease transmission. Emerging infectious diseases, 12(12), 1822.

Petitpierre, B., McDougall, K., Seipel, T., Broennimann, O., Guisan, A., \& Kueffer, C. (2016). Will climate change increase the risk of plant invasions into mountains?. Ecological Applications, 26(2), 530-544.

Phillips SJ, Anderson RP, and Schapire RE. 2006. Maximum entropy modeling of species geographic distributions. Ecological Modelling 190:231-259. https://doi.org/10.1016/j.ecolmodel.2005.03.026

Phillips, S. J., \& Dudík, M. (2008). Modeling of species distributions with Maxent: new extensions and a comprehensive evaluation. Ecography, 31(2), 161-175.

Prasad, P. V., Staggenborg, S. A., Ristic, Z., Ahuja, L. R., Reddy, V. R., Saseendran, S. A., \& Yu, Q. (2008). Response of crops to limited water: Understanding and modeling water stress effects on plant growth processes (Advances in agricultural systems modeling series 1).

Rogelj, J., Meinshausen, M., \& Knutti, R. (2012). Global warming under old and new scenarios using IPCC climate sensitivity range estimates. Nature climate change, 2(4), 248-253.

Rong Z, Zhao C, Liu J, Gao Y, Zang F, Guo Z, Mao Y, and Wang L. 2019. Modeling the Effect of Climate Change on the Potential Distribution of Qinghai Spruce (Picea crassifolia Kom.) in Qilian Mountains. Forests 10:62.

Roseberg, R. J., Norberg, S., Smith, J., Charlton, B., Rykbost, K., \& Shock, C. (2005). Yield and quality of teff forage as a function of varying rates of applied irrigation and nitrogen. Klamath Experiment Station, 1069, 119-136.

PeerJ reviewing PDF | (2020:07:50911:2:1:NEW 8 Jan 2021) 
691 Rosell, C. M., Barro, F., Sousa, C., \& Mena, M. C. (2014). Cereals for developing gluten-free

692

693

694

695

696

697

698

699

700

701

702

703

704

705

706

707

708

709

710

711

712

713

714

715

716

717

718

719

720

721

722

723

724

725

726

727

728

729

730

731

732

733

734

735 products and analytical tools for gluten detection. Journal of Cereal Science, 59(3), 354364.

Rushton, S. P., Ormerod, S. J., \& Kerby, G. (2004). New paradigms for modelling species distributions?. Journal of applied ecology, 41(2), 193-200.

Segele ZT, Lamb PJ, Leslie LM (2009) Large-scale atmospheric circulation and global sea surface temperature associations with Horn of Africa June-September rainfall. Int J Climatol 29:1075-1100

Seleshi, Y., \& Zanke, U. (2004). Recent changes in rainfall and rainy days in Ethiopia. International Journal of Climatology: A Journal of the Royal Meteorological Society, 24(8), 973-983.

Sen, S., Gode, A., Ramanujam, S., Ravikanth, G., \& Aravind, N. A. (2016). Modeling the impact of climate change on wild Piper nigrum (Black Pepper) in Western Ghats, India using ecological niche models. Journal of plant research, 129(6), 1033-1040.

Solomon, S., Manning, M., Marquis, M., \& Qin, D. (2007). Climate change 2007-the physical science basis: Working group I contribution to the fourth assessment report of the IPCC (Vol. 4). Cambridge university press.

Stocker TF, Qin D, Plattner G-K, Tignor M, Allen SK, Boschung J, Nauels A, Xia Y, Bex V, and Midgley PM. 2013. Climate change 2013: The physical science basis. Cambridge University Press Cambridge.

Suwannatrai, A., Pratumchart, K., Suwannatrai, K., Thinkhamrop, K., Chaiyos, J., Kim, C. S., ... \& Sripa, B. (2017). Modeling impacts of climate change on the potential distribution of the carcinogenic liver fluke, Opisthorchis viverrini, in Thailand. Parasitology research, 116(1), 243-250.

Taffesse, A. S., Dorosh, P., \& Gemessa, S. A. (2012). Crop production in Ethiopia: Regional patterns and trends. Food and agriculture in Ethiopia: Progress and policy challenges, 53-83.

Tan, Z., Yang, Y., Wang, Y., Wang, L., \& Sun, G. (2016). The decrease of potential suitable areas and the distribution tendency of staple crops in Ethiopia under future climate conditions. African Journal of Agricultural Research, 11(24), 2092-2101.

Taylor, K. E., Stouffer, R. J., \& Meehl, G. A. (2012). An overview of CMIP5 and the experiment design. Bulletin of the American Meteorological Society, 93(4), 485-498.

Tefera, A., \& Quintin, G. (2012). Ethiopia: grain and feed annual report. Global Agricultural Information Network. USDA Foreign Agriculture Service, Report Number ET, 1201.

Tilamun, Helina \& Schmidt, Emily, 2012. "Spatial Analysis of Livestock Production Patterns in Ethiopia:," ESSP working papers 44, International Food Policy Research Institute (IFPRI).

Tognelli, M. F., Roig, S. A., Marvaldi, A., Flores, G. E., \& Lobo, J. M. (2009). An evaluation of methods for modelling distribution of Patagonian insects.

Turner, N. C., \& Rao, K. P. C. (2013). Simulation analysis of factors affecting sorghum yield at selected sites in eastern and southern Africa, with emphasis on increasing temperatures. Agricultural Systems, 121, 53-62.

VanBuren, R., Wai, C. M., Wang, X., Pardo, J., Yocca, A. E., Wang, H., ... \& Messing, J. (2020). Exceptional subgenome stability and functional divergence in the allotetraploid Ethiopian cereal teff. Nature communications, 11(1), 1-11. 
736

737

738

739

740

741

742

743

744

745

746

747

748

749

750

751

752

753

754

755

756

757

758

759

760

761

762

763
Viste, E., Korecha, D., \& Sorteberg, A. (2013). Recent drought and precipitation tendencies in Ethiopia. Theoretical and Applied Climatology, 112(3-4), 535-551.

Wei, B., Wang, R., Hou, K., Wang, X., \& Wu, W. (2018). Predicting the current and future cultivation regions of Carthamus tinctorius L. using MaxEnt model under climate change in China. Global Ecology and Conservation, 16, e00477.

Wiens, J. A., Stralberg, D., Jongsomjit, D., Howell, C. A., \& Snyder, M. A. (2009). Niches, models, and climate change: assessing the assumptions and uncertainties. Proceedings of the National Academy of Sciences, 106(Supplement 2), 19729-19736.

Wondimu, A. and Tekabe, F. (2001) Utilization of Teff in the Ethiopian Diet. Narrowing the Rift. Teff Research and Development: Proceedings of the International Workshop on Teff Genetics and Improvement, Debre Zeit, 16-19 October 2000, 239-244.

Worku, G., Teferi, E., Bantider, A., \& Dile, Y. T. (2019). Observed changes in extremes of daily rainfall and temperature in Jemma Sub-Basin, Upper Blue Nile Basin, Ethiopia. Theoretical and Applied Climatology, 135(3-4), 839-854.

Yang, M., Li, Z., Liu, L., Bo, A., Zhang, C., \& Li, M. (2020). ecological niche modeling of Astragalus membranaceus var. mongholicus medicinal plants in inner Mongolia, china. Scientific reports, 10(1), 1-18.

Yumbya, J., Maria, D., Vaate, B. D., Kiambi, D., Kebebew, F., \& Rao, K. P. C. (2014). Assessing the effects of climate change on teff in Ethiopia: Implications for food security. Technical report.

Zimmermann, N. E., Edwards Jr, T. C., Graham, C. H., Pearman, P. B., \& Svenning, J. C. (2010). New trends in species distribution modelling. Ecography, 33(6), 985-989.

Pearson's correlation coefficient attached (see Table S1), Correlation of environmental variables. Variables Bio2, Bio3, Bio4, Bio7, Bio11, Bio14, Bio15, Bio18, and Bio19 were deemed independent and used in subsequent analyses. 


\section{Figure 1}

Left: The crop teff, a fine-grain annual cereal. (Source: FAO

http://www.fao.org/traditional-crops/teff/en/) Right: Injera made from teff is a staple food product in Ethiopia.

A

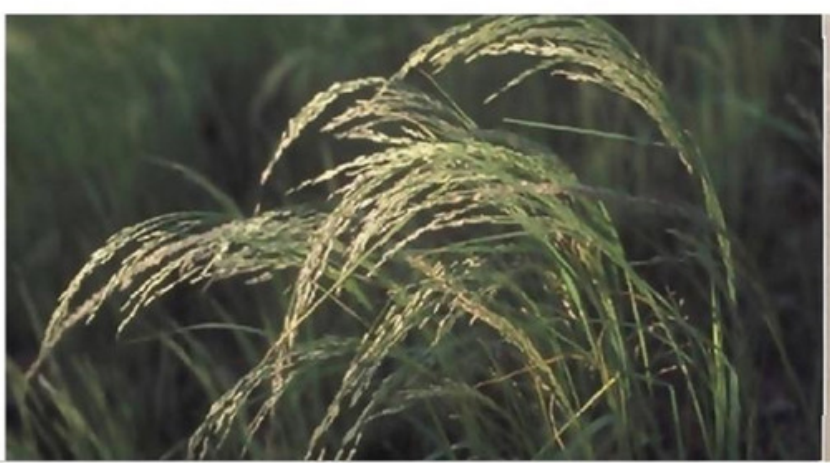

B

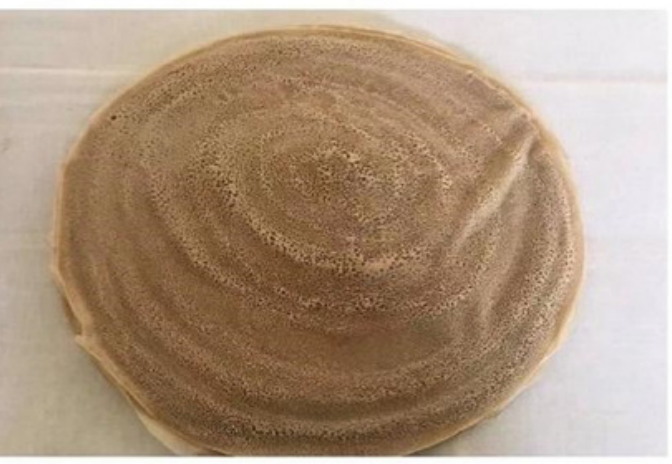

Photo by Gamechis E. Hambisa 
Figure 2

Figure 2 Workflow of the Study 


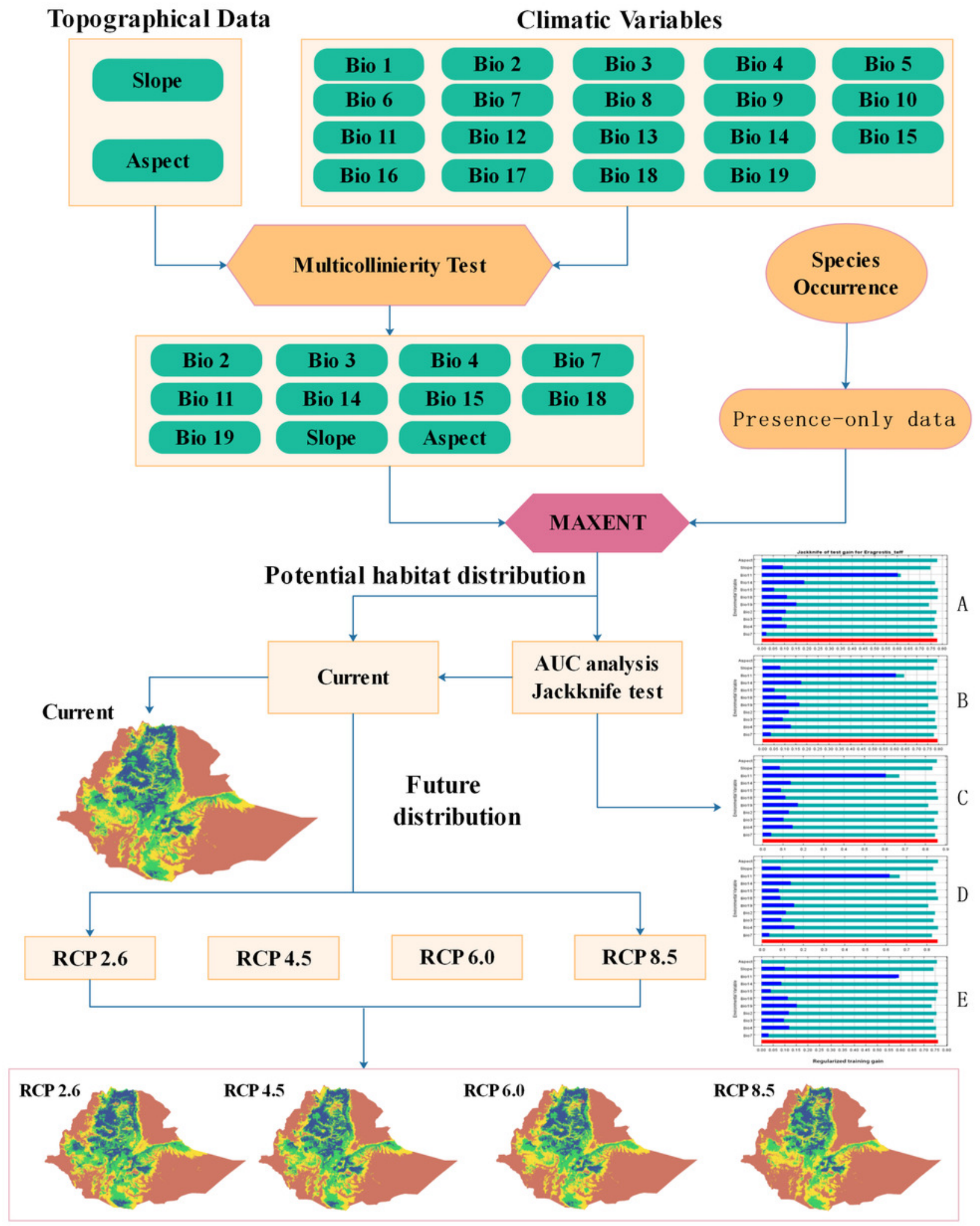


Figure 3

Locations of sampling sites and land elevation within the nine Ethiopian regional state administrations: Oromia, Amhara, Tigray, Afar, Benishangul-Gamuz, Gambella, Harari, Southern Region, and Somali Region.

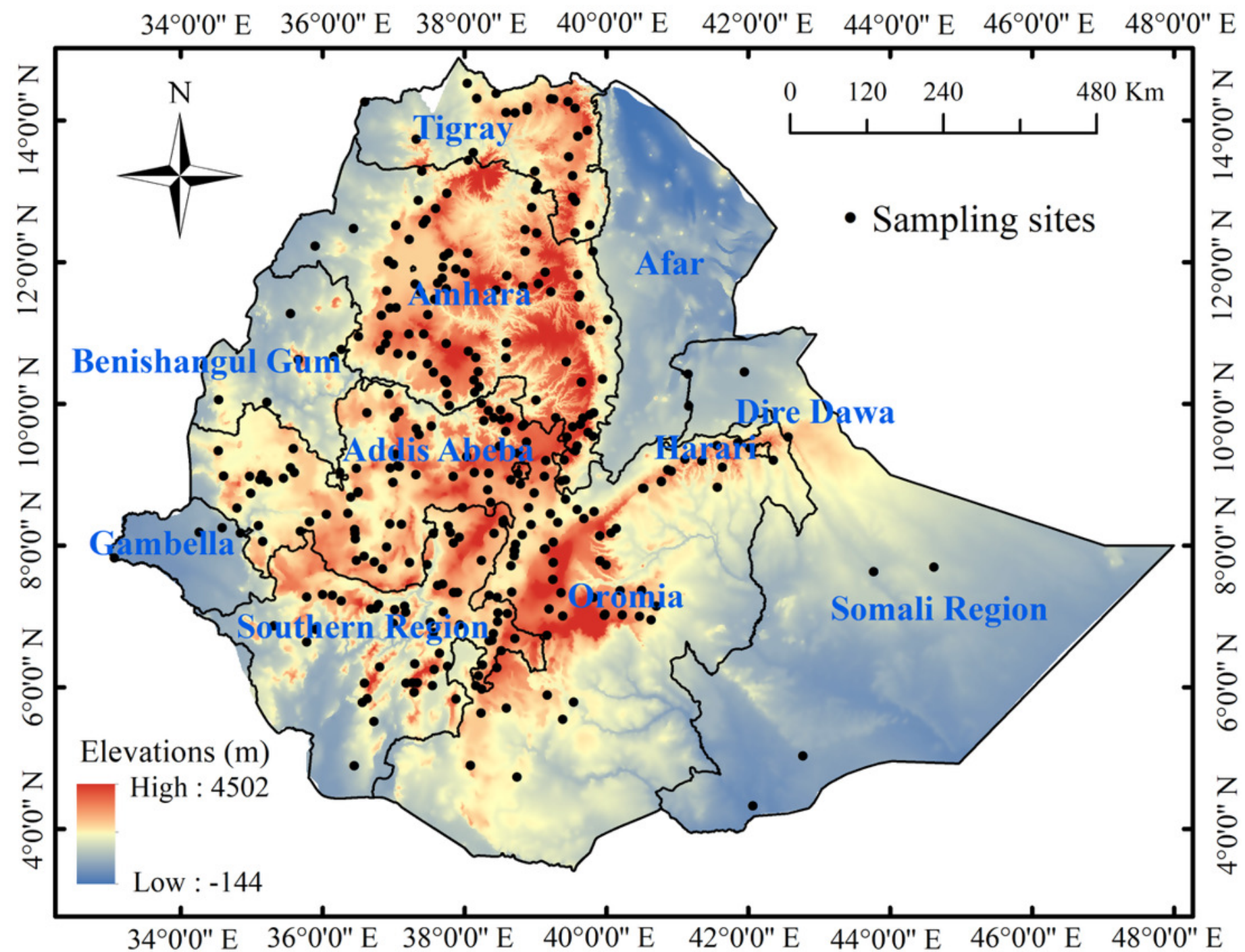


Figure 4

Jackknife test variables contributions to potential distribution of teff distribution under (A) current climate condition scenario, (B) RCP 2.6 scenario, (C) RCP 4.5 scenario, (D) RCP 6.0 scenario, and (E) RCP 8.5 scenario. (The regularized training 


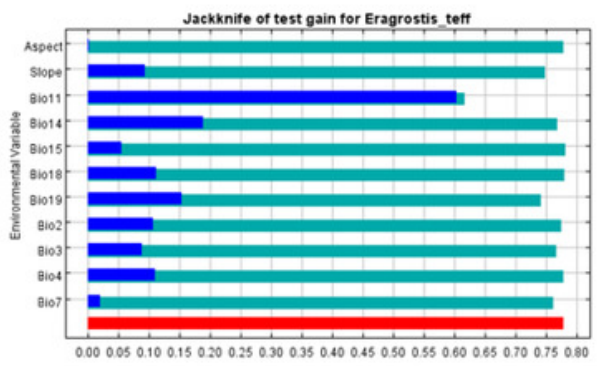

A

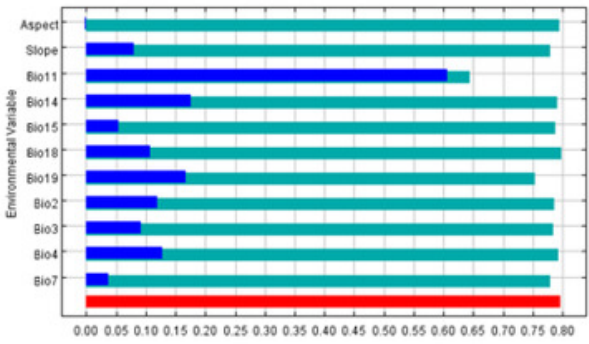

B

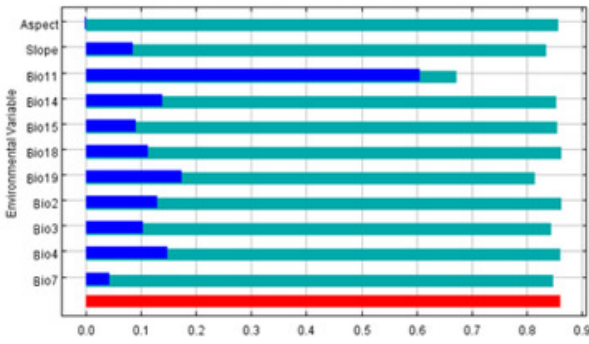

C

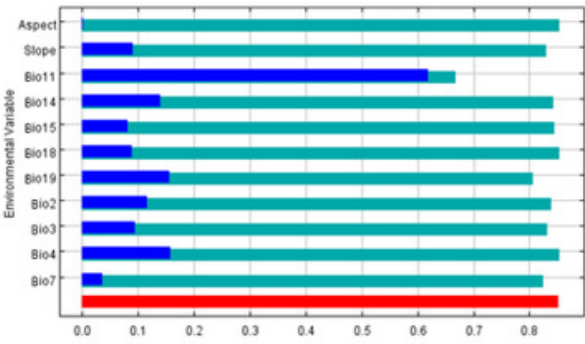

D

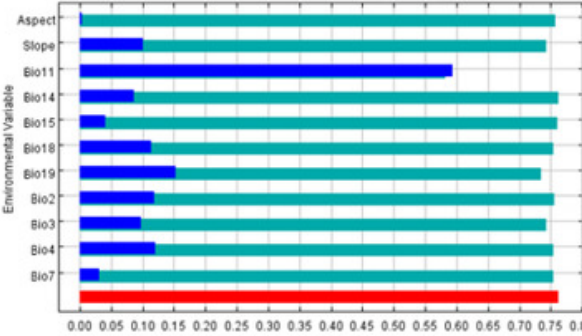

Regularized training gain

With only variatle What variable With all variables 
Figure 5

Figure 4. Response curves of 8 environmental variables in the teff habitat distribution model. A:Bio11( Mean temperature of coldest season $\left({ }^{\circ} \mathrm{C} * 10\right)$ ); B: Bio15( Precipitation seasonality (CV)); C: Bio7( Temperature annual range (Bio5-Bio6));D: Bio19( Precip 

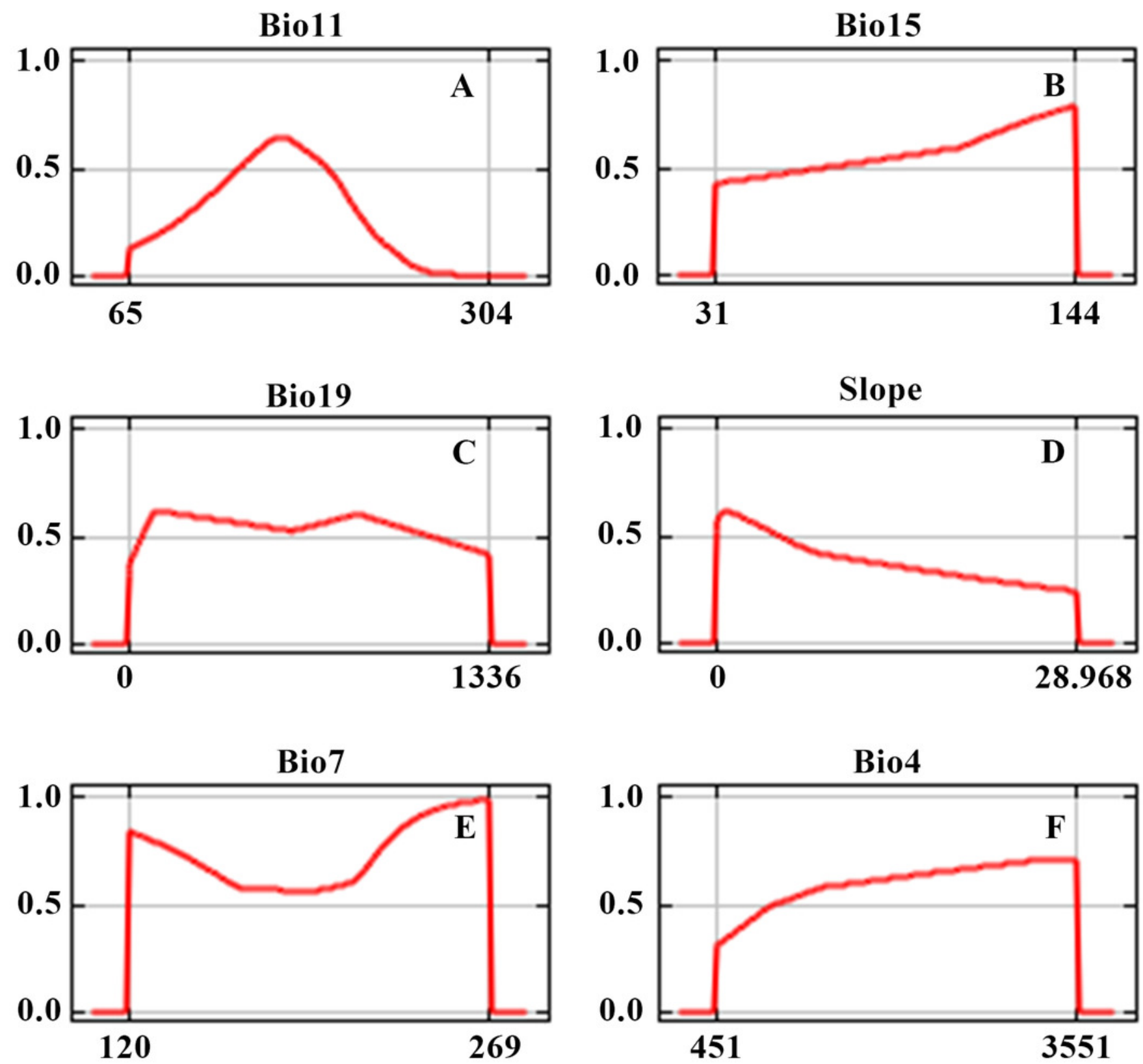

Bio14

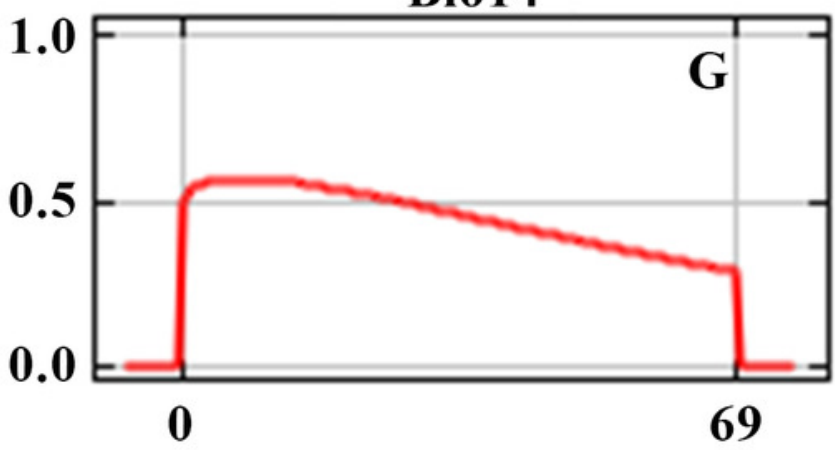

Bio3

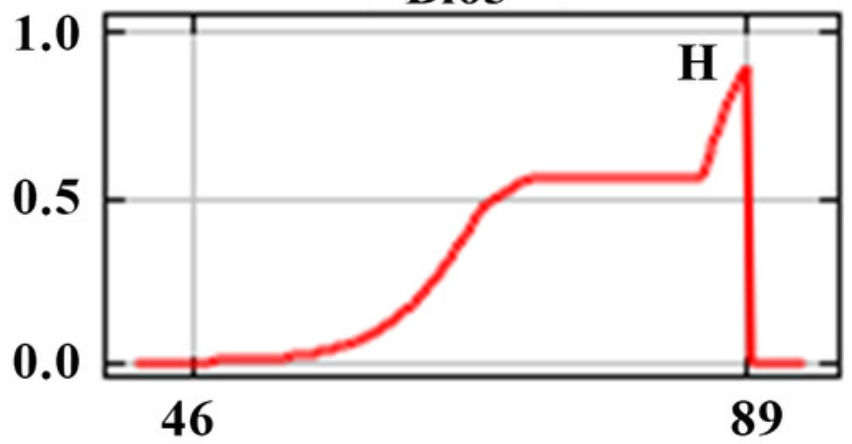


Figure 6

Average annual rainfall (A) and average annual temperature (B) in Ethiopia over three decades.

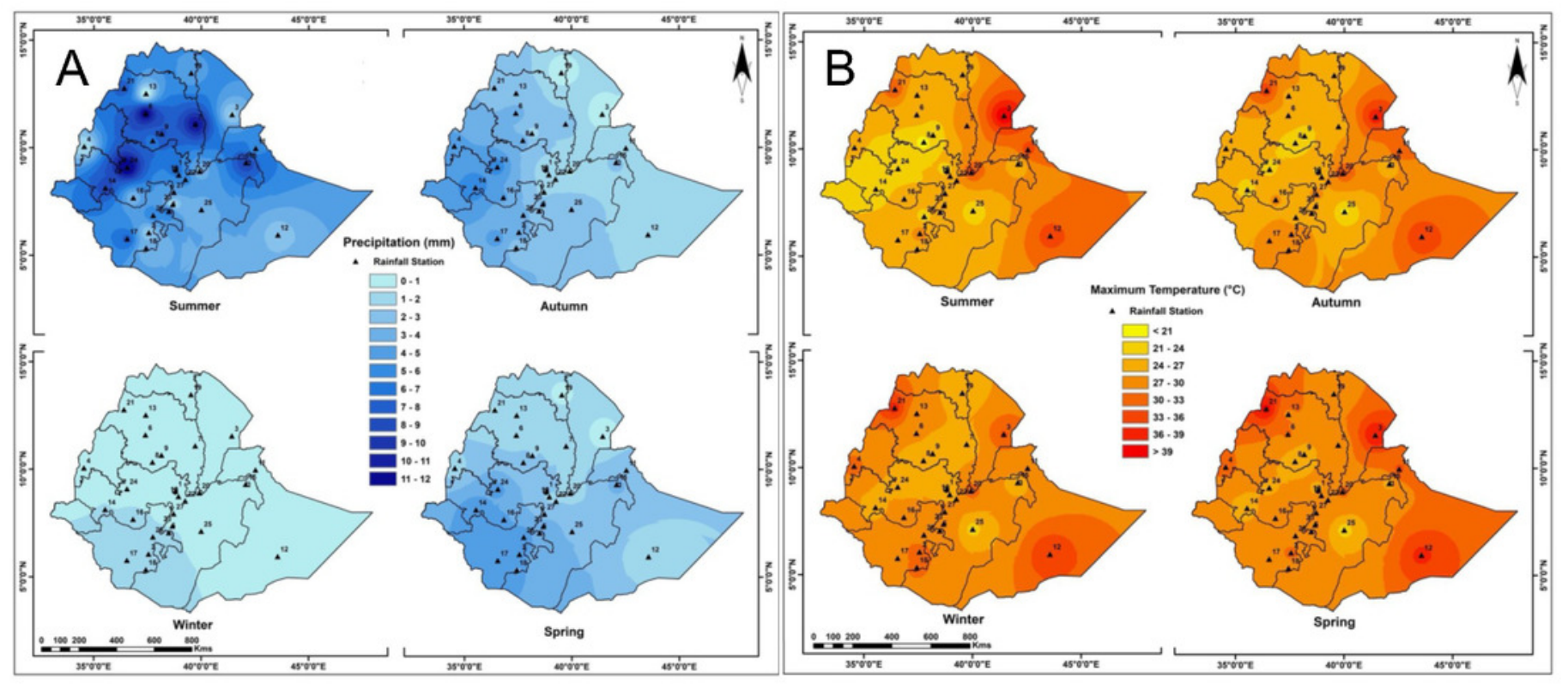




\section{Figure 7}

Figure 6. Distribution of unsuitable, and low, moderate, and highly suitable teff habitats based on current and future distribution under four climate scenarios (Note: A: current; B: RCP 2.6; C: RCP4.5; D: RCP6.0; E: RCP8.5)

Figure 6. Distribution of unsuitable, and low, moderate, and highly suitable teff habitats based on current and future distribution under four climate scenarios.
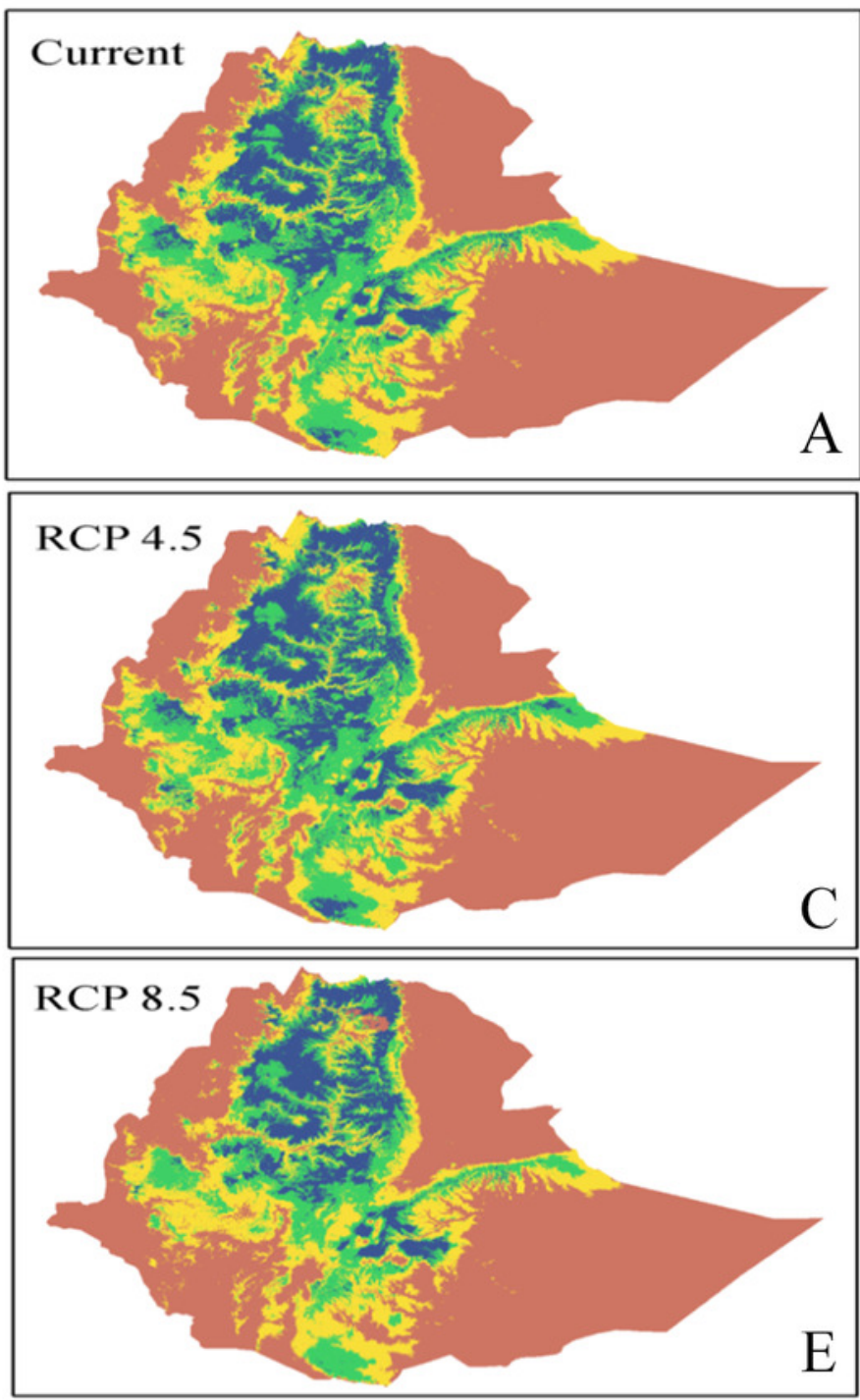
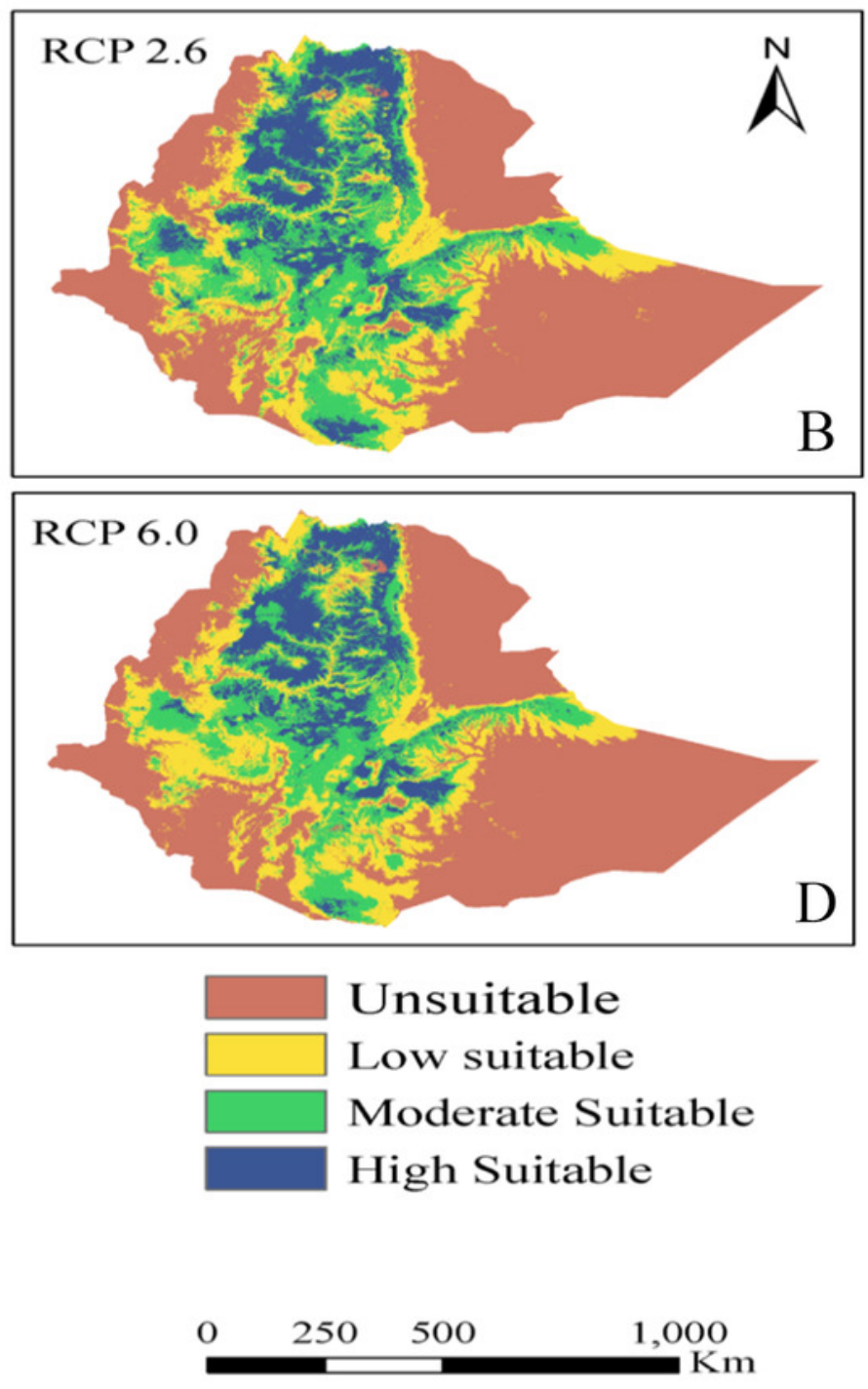


\section{Table 1 (on next page)}

Percent contributions of the variables to teff distribution in the MaxEnt model. 
1 Table 1. Percent contributions of the variables to teff distribution in the MaxEnt model.

2

\begin{tabular}{|c|c|c|c|c|c|c|c|}
\hline \multirow{2}{*}{ Code } & \multirow{2}{*}{ Environmental factor } & \multicolumn{6}{|c|}{ Percent Contribution } \\
\hline & & Unit & Current & $\mathrm{RCP} 2.6$ & $\mathrm{RCP} 4.5$ & RCP6.0 & RCP8.5 \\
\hline $\mathrm{BIO} 1$ & Annual mean temperature & ${ }^{\circ} \mathrm{C}$ & & & & & \\
\hline BIO2 & $\begin{array}{l}\text { Mean diurnal range (Monthly max. min. and } \\
\text { mean temp.) }\end{array}$ & ${ }^{\circ} \mathrm{C}$ & 0.23 & 0.6 & 0.2 & 0.5 & 0.40 \\
\hline BIO3 & Isothermality $(\mathrm{Bio} 2 / \mathrm{Bio} 7 \times 100)$ & & 1.11 & 1.3 & 0.9 & 1.3 & 0.81 \\
\hline BIO4 & $\begin{array}{l}\text { Temperature seasonality (standard } \\
\text { deviation } \times 100 \text { ) }\end{array}$ & & 1.33 & 0.8 & 0.5 & 0.45 & 0.44 \\
\hline $\mathrm{BIO} 5$ & Maximum temperature of warmest month & ${ }^{\circ} \mathrm{C}$ & & & & & \\
\hline BIO6 & Minimum temperature of coldest month & ${ }^{\circ} \mathrm{C}$ & & & & & \\
\hline BIO7 & Temperature annual range (Bio5-Bio6) & ${ }^{\circ} \mathrm{C}$ & 2.17 & 2.6 & 2.3 & 2.85 & 2.39 \\
\hline $\mathrm{BIO} 8$ & Mean temperature of wettest quarter & ${ }^{\circ} \mathrm{C}$ & & & & & \\
\hline BIO9 & Mean temperature of driest season & ${ }^{\circ} \mathrm{C}$ & & & & & \\
\hline BIO10 & Mean temperature of warmest season & ${ }^{\circ} \mathrm{C}$ & & & & & \\
\hline BIO11 & Mean temperature of coldest season & ${ }^{\circ} \mathrm{C}$ & 78.3 & 79.7 & 80.4 & 78.5 & 77.8 \\
\hline $\mathrm{BIO} 12$ & Annual precipitation & $\mathrm{mm}$ & & & & & \\
\hline $\mathrm{BIO} 13$ & Precipitation of wettest period & $\mathrm{mm}$ & & & & & \\
\hline BIO14 & Precipitation of driest period & $\mathrm{mm}$ & 1.3 & 1.1 & 0.8 & 1.35 & 1.49 \\
\hline BIO15 & Precipitation seasonality (CV) & & 8.3 & 7.3 & 7.8 & 7.76 & 9.04 \\
\hline $\mathrm{BIO} 16$ & Precipitation of wettest season & $\mathrm{mm}$ & - & - & - & - & - \\
\hline $\mathrm{BIO} 17$ & Precipitation of driest season & $\mathrm{mm}$ & & & & & \\
\hline BIO18 & Precipitation of warmest season & $\mathrm{mm}$ & 0.2 & 0.2 & 0.1 & 0.14 & 0.03 \\
\hline BIO19 & Precipitation of coldest season & $\mathrm{mm}$ & 3.7 & 2.9 & 3.5 & 3.90 & 4.32 \\
\hline SLOP & Slope & $\circ$ & 3.3 & 3.2 & 3.5 & 3.09 & 3.10 \\
\hline ASP & Aspect & $\circ$ & 0.1 & 0.1 & 0.2 & 0.1 & 0.09 \\
\hline
\end{tabular}

3

4 Note: The variables in bold were key variables selected by their contribution rates and multicollinearity test.

5 RCP: (Representative Concentration Pathway).

6 
Table 2 (on next page)

Estimates of relative contributions and permutation importance of the predictor environmental variables to the MaxEnt model. 
1 Table 2. Estimates of relative contributions and permutation importance of the predictor

2 environmental variables to the MaxEnt model.

3

\begin{tabular}{|c|c|c|}
\hline Variable & $\begin{array}{c}\text { Percent } \\
\text { Contribution }\end{array}$ & $\begin{array}{c}\text { Permutation } \\
\text { Importance }(\%)\end{array}$ \\
\hline (Bio11) Mean temperature of coldest quarter & 78.3 & 66.5 \\
\hline (Bio15) Precipitation seasonality & 8.3 & 4.7 \\
\hline (Bio19) Precipitation of coldest quarter & 3.7 & 3.8 \\
\hline Slope & 3.3 & 3.9 \\
\hline (Bio7) Temperature annual range & 2.2 & 5.3 \\
\hline (Bio4) Temperature seasonality & 1.3 & 3.1 \\
\hline (Bio14) Precipitation of driest month & 1.3 & 1.8 \\
\hline $\begin{array}{l}\text { Bio3) Isothermality (mean diurnal range/temperature } \\
\text { annual range) }\end{array}$ & 1.1 & 8.4 \\
\hline $\begin{array}{l}\text { (Bio2) Mean diurnal range (mean of monthly temp } \\
\text { range) }\end{array}$ & 0.2 & 1.8 \\
\hline (Bio18) Precipitation of warmest quarter & 0.2 & 1.8 \\
\hline Aspect & 0.1 & 0.4 \\
\hline
\end{tabular}

4 


\section{Table 3(on next page)}

Results of receiver operating characteristic (ROC) analysis under current climate and four future projected scenarios. 
1 Table 3. Results of receiver operating characteristic (ROC) analysis under current climate and 2 four future projected scenarios.

3

\begin{tabular}{llllll}
\hline AUC & Current & RCP2.6 & RCP4.5 & RCP6.0 & RCP8.5 \\
\hline AUC (Training Data) & 0.841 & 0.839 & 0.835 & 0.835 & 0.843 \\
AUC (Test data) & 0.829 & 0.833 & 0.846 & 0.842 & 0.826 \\
\hline
\end{tabular}

4 


\section{Table 4 (on next page)}

The total area of suitable and unsuitable teff habitats based on current distribution data and projected four future climate scenarios. 
1 Table 4. The total area of suitable and unsuitable teff habitats based on current distribution data 2 and projected four future climate scenarios.

\begin{tabular}{llllll}
\hline & Current & RCP2.6 & RCP4.5 & RCP6.0 & RCP8.5 \\
\hline Unsuitable area $\left(\mathrm{km}^{2}\right)$ & 560960 & 549902 & 565720 & 544774 & 568305 \\
Low suitability area $\left(\mathrm{km}^{2}\right)$ & 463453 & 463044 & 434560 & 464483 & 458548 \\
Moderate suitability area $\left(\mathrm{km}^{2}\right)$ & 296933 & 309811 & 320942 & 311603 & 293716 \\
High Suitability area $\left(\mathrm{km}^{2}\right)$ & 14513 & 13102 & 14637 & 14999 & 15290 \\
Total Suitability area $\left(\mathrm{km}^{2}\right)$ & 774899 & 785957 & 770139 & 791085 & 767554 \\
Change area $\left(\mathrm{km}^{2}\right)$ & & 11058 & -4760 & 16186 & -7345 \\
Percent $(\%)$ & 58 & 58.8 & 57.6 & 59.2 & 57.4 \\
\hline
\end{tabular}

3 